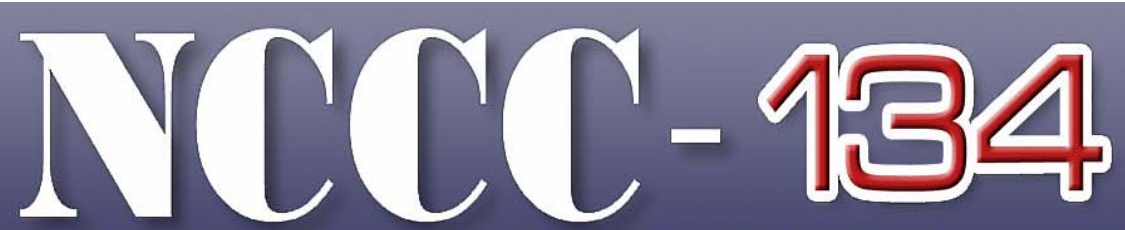

APPLIED COMMODITY PRICE ANALYSIS, FORECASTING AND MARKET RISK MANAGEMENT

\title{
Price and Profit: Investigating a Conundrum
}

by

Carl R. Zulauf, Gary Schnitkey, and Carl T. Norden

Suggested citation format:

Zulauf, C. R., G. Schnitkey, and C. T. Norden. 2006. "Price and Profit:

Investigating a Conundrum." Proceedings of the NCCC-134 Conference on

Applied Commodity Price Analysis, Forecasting, and Market Risk

Management. St. Louis, MO. [http://www.farmdoc.uiuc.edu/nccc134]. 


\title{
PRICE AND PROFIT: INVESTIGATING A CONUNDRUM
}

\author{
Carl R. Zulauf, Gary Schnitkey, and Carl T. Norden* \\ Paper presented at the NCCC-134 Conference on Applied Commodity Price \\ Analysis, Forecasting, and Market Risk Management \\ St. Louis, Missouri, April 17-18, 2006
}

Copyright 2006 by Carl R. Zulauf, Gary Schnitkey, and Carl T. Norden. All rights reserved. Readers may make verbatim copies of this document for non-commercial purposes by any means, provided that this copyright notice appears on all such copies.

* Carl R. Zulauf is McCormick Professor of Agricultural Marketing and Policy, Ohio State University (zulauf.1@osu.edu). Gary Schnitkey is Professor, University of Illinois at UrbanaChampaign, and Carl Norden is a masters student at Purdue University. The authors wish to thank Scott Irwin, Allan Lines, and Wade Brorsen for their comments and insights on an earlier draft of the paper. 


\section{PRICE AND PROFIT: INVESTIGATING A CONUNDRUM}

Practitioner's Abstract: Although few in number, studies consistently find that price explains little, if any, of the variation in profit across farms. This contrasts with farmers' opinions regarding the importance of price, as well as the use of price supports as a primary policy instrument. Using farm level data from the Illinois Farm Business Farm Management program for calendar years 1996 through 2004, a potential explanation for this conundrum is identified. Price is significantly more correlated with a farmer's variation in management return from year to year (approximately, +0.45 ) than with the variation in management return across farmers (approximately, +0.10). Thus, the conundrum arises out of different perspectives: farmers focus on the performance of their own farm over time while studies have focused on the variation among farms.

Keywords: corn, correlation, cross-sectional, price, profit, soybeans, temporal

\section{Introduction}

Although few in number, studies consistently find that price explains little if any of the variation in profit across farms (Sonka, Hornbaker, and Hudson, 1989; El-Osta and Morehart, 2000; and Nivens, Kastens, and Dhuyvetter, 2002). This finding stands in contrast to the importance that farmers assign to managing price risk (for example, Patrick, 1985), to their use of marketing services that provide advice on pricing strategies (Irwin, et. al, 2005, and literature cited therein; Isengildina et al. 2004), and to the reliance on price support programs as a key instrument of U.S. farm policy since the 1930s (U.S. Department of Agriculture, 1984 and 2002).

An explanation for this conundrum is examined using data for a sample of Illinois farms between 1996 and 2004. Specifically, the correlation between price per bushel and profit per acre differs significantly when calculated for a given farm over time than when calculated for a cross section of farms. Consistent with the studies cited above, the correlation for the cross section of farms is close to zero. In contrast, the correlation for a given farm over time is significantly higher. These different correlation structures provide an explanation for the conundrum: farmers focus on the performance of their own farm over time while studies have focused on the variation in performance across different farms.

\section{Literature Review}

Sonka, Hornbaker, and Hudson (1989) examined factors associated with farm performance for 179 cash grain producers participating in the Illinois Farm Business Farm Management project. The data were averaged over the eight year observation period of 1976 through 1983 . Then, the farms were divided into two subgroups: top 25 percent and bottom 25 percent. Logit regressions were estimated using as dependent variables whether or not the farmer was a member of the top performing quartile and the bottom performing quartile. As a sensitivity test, the logit regressions were estimated for the 1976-1979 and 1980-1983 subperiods. The only statistically significant findings that held for the entire observation period and both subperiods were (1) that 
farms in the top performing quartile had lower operating expenses and (2) that farms in the bottom performing quartile had higher operating expenses and lower corn yields.

Using data from the U.S. Department of Agriculture's Agricultural Resource Management Study for 1993, El-Osta and Morehart (2000) examined the impact that technology adoption had on the performance of U.S. dairy farms. In one component of their analysis, they divided the dairy farms into low, middle, and high performance categories. Compared with dairy farms in the low and middle performance categories, high performing farms had higher technical efficiency and lower variable, cash, and total economic cost of production at the 95 percent level of statistical confidence. In contrast, high performing farms received a significantly lower average price for their milk.

Nivens, Kastens, and Dhuyvetter (2002) investigated management factors associated with risk-adjusted profit per acre. They used data for approximately 1000 farms involved in the Kansas Management, Analysis, and Research project from 1990 through 1999. Variables for a farm were indexed to the value of the variable for farmers in the same geographical area. Cost management, planting intensity, and technology adoption had the greatest impact on profit per acre. In contrast, price had a statistically insignificant relationship with profit per acre.

\section{Data}

The data used in this study come from the Illinois Farm Business Farm Management (FBFM) program. FBFM is a farmer-owned cooperative that has a working relationship with the University of Illinois at Urbana-Champaign. Farmer members maintain production and financial records for their farm. At the end of the calendar year accounting period, they transfer information on crop and livestock production, receipts, expenses, inventories, and capital accounts to a central office for processing.

All farms included in this study had their data certified as accurate and complete by FBFM personnel for all nine calendar years from 1996 through 2004. This period is chosen for analysis because preparation and computation of the data are consistent during it.

Management return equals total farm receipts minus expenses. Total receipts equal crop receipts plus livestock receipts plus government payments. Expenses equal the sum of cash expenses, depreciation, and charges for owned land and unpaid family labor.

This study focuses on corn and soybean, the dominant crops in Illinois. To create a data set that is more homogenous on crop production, farms are excluded from the analysis if in any calendar year livestock expenses exceed \$5,000 and/or livestock return net of feed cost is less than $-\$ 10$ per acre or more than $\$ 10$ per acre.

FBFM reports both an old crop price and a new crop price. The old crop price is the average price received for corn (soybean) produced in previous years but sold during the current calendar year. The new crop price is the average price for corn (soybean) produced and sold during the current calendar year. For example, the 2003 report contains an average old crop corn 
price computed for corn produced in earlier years but sold in 2003 and an average new crop corn price computed for corn produced and sold in 2003.

After applying the selection criteria, a complete set of certified data existed for 416 farms that reported a non-zero old corn price for all years, for 110 farms that reported a non-zero new crop corn price for all years, for 391 farms that reported a non-zero old crop soybean price for all years, and for 70 farms that reported a non-zero new crop soybean price for all years. A zero price indicated that a farmer did not sell any of that crop during the calendar year. These four files comprise the data set for this study.

The same farm can be an observation in all four data files. While price varies across the four files for a given farm and yield varies between corn and soybean, the other variables, notably management return, are the same for a farm. Hence, the analyses of the four data files are not independent and should be considered sensitivity tests.

The variations in price within a year and over the observation period are illustrated in figure 1 using the old corn price data. The average old crop corn price varies from $\$ 1.94$ per bushel in 2000 to $\$ 3.43$ per bushel in 1996. The lowest price observed for a year averages 26 percent under the mean price for the year. The highest observed price for a year averages 29 percent over the mean price for the year.

\section{Methodology}

A Pearson correlation coefficient between price and management return is calculated for each year. It measures how price varies with management return across all farms in a data file for a year. Nine cross sectional correlations are calculated for each data file, one for each year. These nine correlations are averaged. To illustrate using the old crop corn price data file, a correlation is calculated between old corn price per bushel and management return per acre for 1996 using the data for the 416 farms in this file. The correlation for 1996 is averaged with the same correlation computed for each of the eight years between 1997 and 2004. Subsequently, this average correlation is referred to as the correlation across farms.

The price-management return correlation also is calculated for each farm using the farm's data for the nine years from 1996 through 2004. It measures how price varies with management return over time for a given farm. The correlation computed for all farms in a data file are averaged. To illustrate using the old crop corn price data file, a correlation is calculated between old corn price per bushel and management return per acre for each of the 416 farms in this data file. Each correlation is computed using a farm's data for 1996 through 2004 . The 416 correlations computed for the old crop corn price data file are averaged. Subsequently, this average correlation is referred to as the correlation over time.

A t-test for the difference between two means is used to test whether the average correlation computed across farms differs significantly from the average correlation computed over time (Hoel, 1971, pg. 262-265). An F-test finds that the standard deviation of the correlation over time is significantly different than the standard deviation of the correlation 
across farms at the 95 percent level of statistical confidence. Standard deviation of the correlation over time is larger (see table 1). Thus, the t-test is computed for the difference between two means with different variances.

The null and alternative hypotheses are

(1) $\mathrm{H}_{\mathrm{NULL}}$ : mean correlation across farms - mean correlation over time $=0$

(2) $\mathrm{H}_{\text {ALTERNATIVE: }}$ mean correlation across farms - mean correlation over time $\neq 0$

A two-tailed t-test is used because there is no a priori reason to expect the correlation across farms to be higher or lower than the correlation over time.

\section{Results}

The mean correlation across farms between price and management return per acre ranges from +0.04 (corn new price file) to +0.14 (corn old price file) (see table 1 and figure 2). In contrast, the mean correlation over time between price and management return per acre ranges from +0.42 (soybean old price file) to +0.48 (corn old price and soybean new price files). Furthermore, all four t-tests are significant at the 99 percent level of statistical confidence (see table 1). Thus, the variation in price received by a farmer over time is more closely related with the farmer's variation in management return over time than is the variation in price across farmers associated with the variation in management return across farmers.

Reinforcing this finding is a comparison with the correlations between management return and two other variables commonly investigated, yield and non-land cost per acre (see table 1). The price-management return correlation over time substantially exceeds the yieldmanagement return correlation over time and is the same absolute value as the cost-management return correlation over time. Thus, relative to the variation in yield and cost, a farmer perceives that the variation in price is an important determinant of the variation in his/her management return over time. In contrast, the price-management return correlation across farms is substantially smaller than both the yield-management return correlation across farms and the cost-management return correlation across farms. This finding is consistent with previous research.

\section{Summary, Conclusions, and Implications}

Although few in number, studies have consistently found that price explains little, if any, of the variation in profit across farms. This finding stands in contrast both to farmers' opinion regarding the importance of price and to the longstanding use of price supports as a primary policy instrument to support farm income.

Using data from a sample of Illinois farmers between 1996 and 2004, this study finds that this conundrum can be explained by differences in correlation structure. In particular, the variation in price received by a farmer is found to be significantly more correlated with that farmer's variation in management return from year to year (approximately, +0.45) than is the variation in price across farmers correlated with the variation in management return across 
farmers (approximately, +0.10). Thus, the conundrum can be explained by a difference in perspective. Farmers conclude that price matters because they are looking across time at the performance of their own farm. In contrast, researchers concluded that price has limited explanatory power because they examined the performance of more than one farm at the same point in time.

Two issues for further research are explored. One is measurement error-in particular not adjusting price to a net harvest basis by subtracting storage and interest costs between harvest and the date the crop is sold. Such an adjustment could not be made in the current study because the specific dates on which the crop was sold are not available. It is possible that adjusting price for storage and interest costs could result in correlation structures that are more similar across farms and over time. On the other hand, the difference between the price-management return correlations across farms and over time is essentially the same for the old and new crop price files. Because corn and soybean harvest begins in September in Illinois and the accounting year ends in December, storage and interest costs are a smaller share of new crop prices than of old crop prices. While this last observation does not remove the need to adjust price for storage and interest costs, it does suggest that this measurement error probably does not explain the entire difference found between correlations across farms and over time.

The second issue revolves around a commonly-stated implication drawn from the finding that price does not explain much of the variation in profit across farms. Specifically, as a group, farmers have no ability to price crops better than the market average price. Can this conclusion still hold given the finding of a statistically significant relationship between price and profit over time for an individual farmer? The answer is yes if the own price elasticity of demand is inelastic and a farmer's yield is positively correlated with national production. Given these two conditions, low (high) production means both a high (low) price and a high (low) management return because price increases (decreases) by a greater percentage than yield declines (increases). Hence, even if a producer sells at the same time every year, a positive correlation between price and management return can result from the year-to-year variation in production. Thus, finding a positive correlation over time between price and management return is not necessarily an indication that a farmer has the ability to successfully time the pricing of a crop.

In conclusion, further investigation is needed to better understand the correlation between price and profit and the factors that affect it. Nevertheless, this study finds that the wide-spread belief among farmers that price is a key determinant of profit has an empirical basis in farmers' experiences, even if it is an empirical basis over which they may have little control. Moreover, the findings of this study suggest that it can be inappropriate to use the correlation structure estimated for the variation in economic performance across farms at a point in time to examine issues regarding the variation in economic performance of a farm over time. 


\section{References}

El-Osta, Hisham S. and Mitchell J. Morehart. "Technology Adoption and Its Impact on Production Performance of Dairy Operations." Review of Agricultural Economics 22(Fall/Winter 2000): 477-498.

Hoel, Paul G. Introduction to Mathematical Statistics. Fourth Edition. John Wiley and Sons, Inc.: New York. 1971.

Irwin, Scott H., Darrel L. Good, Joao Martines-Filho, and Lewis A. Hagedorn. "The Pricing Performance of Market Advisory Services in Corn and Soybeans Over 1995-2003." University of Illinois at Urbana-Champaign AgMAS Research Report 2005-01. March 2005. [Accessed January 2006 at http://www.farmdoc.uiuc.edu/agmas/]

Isengildina, Olga, Joost M. E. Pennings, Scott H. Irwin, and Darrel L. Good. "Crop Farmers' Use of Market Advisory Services." University of Illinois at Urbana-Champaign AgMAS Research Report 2004-03. July 2004. [Accessed January 2006 at http://www.farmdoc.uiuc.edu/agmas/]

Nivens, Heather D., Terry L. Kastens, and Kevin C. Dhuyvetter. "Payoffs to Farm Management: How Important Is Crop Marketing?" Journal of Agricultural and Applied Economics 34(April 2002): 193-204.

Patrick, George R., Paul N. Wilson, Peter J. Barry, William G. Boggess, and Douglas L. Young. "Risk Perceptions and Management Responses: Producer-Generated Hypotheses for Risk Modeling." Southern Journal of Agricultural Economics 17(December 1985): 231-238.

Sonka, Steven T., Robert H. Hornbaker, and Michael A. Hudson. "Managerial Performance and Income Variability for a Sample of Illinois Cash Grain Producers." North Central Journal of Agricultural Economics 11(January 1989): 39-47.

U.S. Department of Agriculture, Economic Research Service. History of Agricultural PriceSupport and Adjustment Programs, 1933-84. Agriculture Information Bulletin No. 485. December 1984.

U.S. Department of Agriculture, Economic Research Service. "2002 Farm Bill --- Side by Side Comparison --- 1996 and 2002 Farm Bills." 2002. Accessed January 2006 at http://www.ers.usda.gov/Features/farmbill/titles/titleIcommodities.htm 
Table 1. Correlations between Farm Management Return per Acre and Selected Variables, Illinois, 1996-2004

\begin{tabular}{lcccccc}
\hline \multirow{2}{*}{$\begin{array}{l}\text { Statistical Measure } \\
\text { by Data File }\end{array}$} & \multicolumn{3}{c}{ Correlation Across Farms } & \multicolumn{3}{c}{ Correlation Over Time } \\
\cline { 2 - 7 } & Price & Yield & Cost & Price & Yield & Cost \\
\hline \multirow{2}{*}{ Corn Old Price File } & & & & & & \\
Mean & 0.14 & 0.28 & -0.66 & $0.48^{* *}$ & 0.27 & $-0.51^{* *}$ \\
Minimum & 0.01 & 0.18 & -0.75 & -0.71 & -0.82 & -0.96 \\
Maximum & 0.28 & 0.45 & -0.52 & 0.93 & 0.88 & 0.62 \\
Stan. Dev. & 0.10 & 0.09 & 0.07 & 0.30 & 0.35 & 0.33
\end{tabular}

Corn New Price File

$\begin{array}{lrrrrrc}\text { Mean } & 0.04 & 0.30 & -0.56 & 0.46^{* *} & 0.29 & -0.44^{*} \\ \text { Minimum } & -0.18 & 0.16 & -0.79 & -0.55 & -0.47 & -0.96 \\ \text { Maximum } & 0.32 & 0.53 & -0.38 & 0.90 & 0.86 & 0.62 \\ \text { Stan. Dev. } & 0.17 & 0.12 & 0.15 & 0.26 & 0.32 & 0.37\end{array}$

Soybean Old Price File

$\begin{array}{lrrrrrc}\text { Mean } & 0.09 & 0.26 & -0.67 & 0.42^{* *} & 0.09^{* *} & -0.50^{* *} \\ \text { Minimum } & -0.09 & 0.16 & -0.76 & -0.59 & -0.74 & -0.96 \\ \text { Maximum } & 0.24 & 0.41 & -0.54 & 0.89 & 0.90 & 0.62 \\ \text { Stan. Dev. } & 0.10 & 0.07 & 0.07 & 0.26 & 0.33 & 0.33\end{array}$

Soybean New Price File

Mean

Minimum

Maximum

Stan. Dev.

\subsection{1}

$-0.09$

0.29

0.12
0.36

0.12

0.57

0.14
$-0.54$

$-0.80$

$-0.39$

0.13
$0.48^{* *}$

$-0.21$

0.88

0.24
$0.15^{* *}$

$-0.58$

0.75

0.33
$-0.49$

$-0.96$

0.52

0.37

Notes: (a) Correlation across farms is the average of correlations between management return and another variable calculated for each year from 1996 through 2004. This correlation is calculated using the data for all farms in a year. Correlation across time is the average of the correlations between management return and another variable for each farm in the data set. This correlation is calculated using the farm's data for 1996 through 2004. (b) Null hypothesis is (correlation across farms - correlation over time) $=0$. (c) t-tests for price, yield, and cost, respectively, by data file are: Corn Old Price: 9.41, -0.18, 5.24; Bean Old Price: 10.44, -4.37, 4.20; Corn New Price: 6.71, -0.05, 2.00; and Bean New Price: 7.36, -3.50, 0.82. (d) ** and * indicate a significant t-test at the $99 \%$ and $95 \%$ levels of statistical confidence, respectively.

SOURCE: original calculations using data from the Illinois Farm Business Farm Management program 


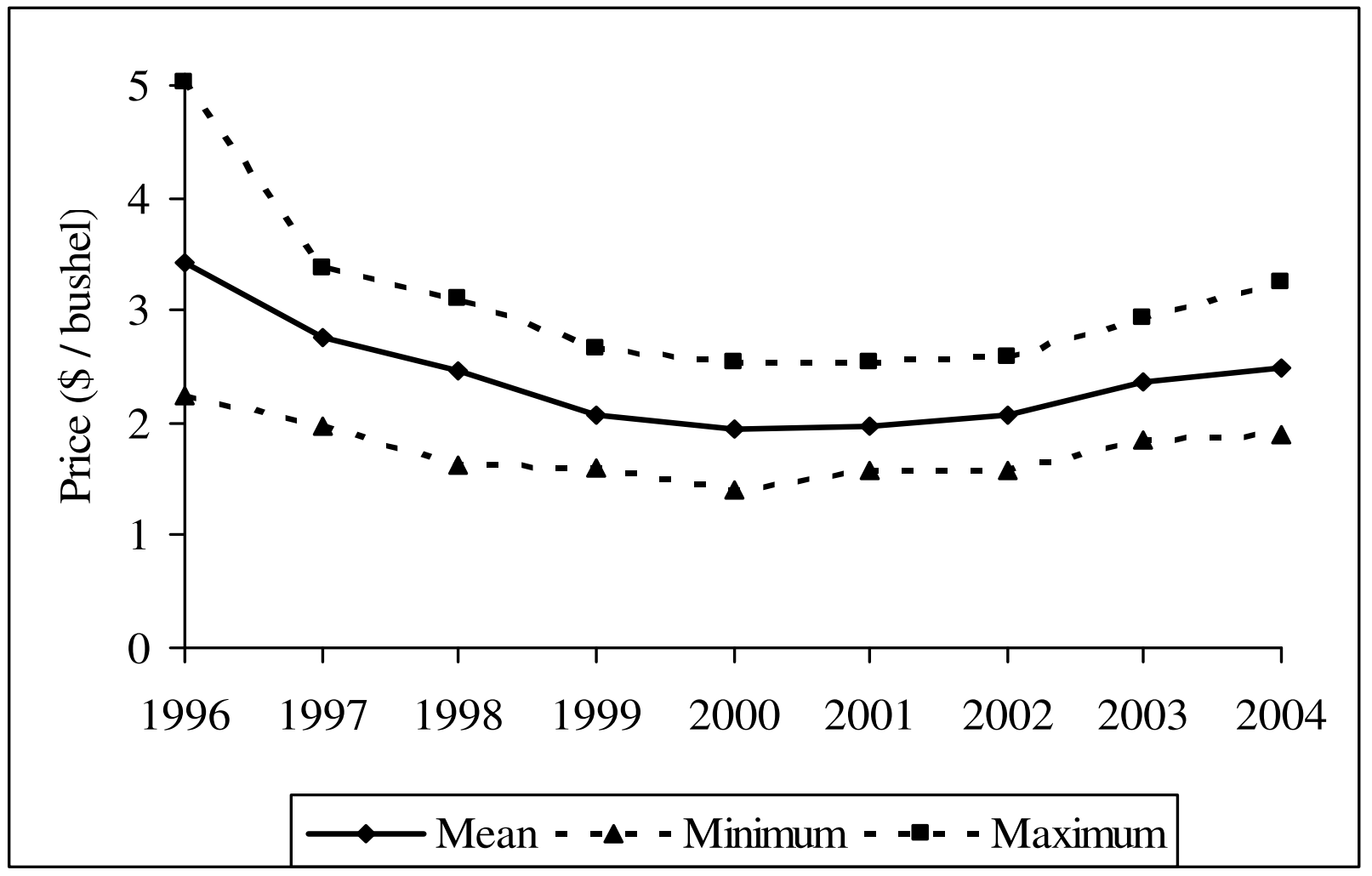

Figure 1. Mean, minimum, and maximum price among farmers who sold corn from previous crop by year, Illinois, 1996-2004

SOURCE: original calculations using data from the Illinois Farm Business Farm Management program 


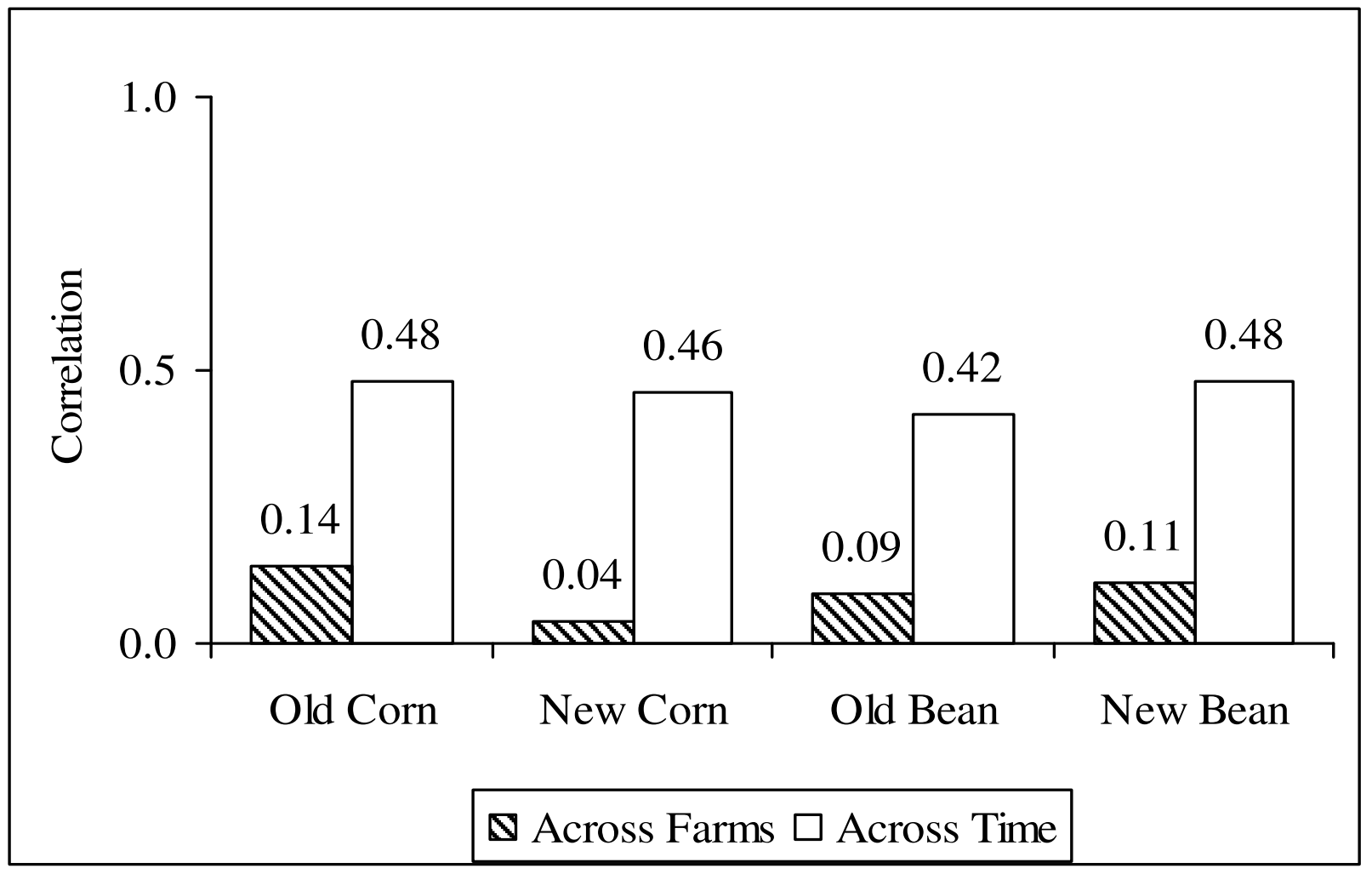

Figure 2. Correlations between management return per acre and price by data file, Illinois, 1996-2004

Note: Correlation across farms is the average of the correlations between management return and another variable calculated for each year from 1996 through 2004. This correlation is calculated using the data for all farms in a year. Correlation across time is the average of the correlations between management return and another variable for each farm in the data set. This correlation is calculated using the farm's data for 1996 through 2004.

SOURCE: original calculations using data from the Illinois Farm Business Farm Management program 